University of Louisville

ThinkIR: The University of Louisville's Institutional Repository

Electronic Theses and Dissertations

1938

\title{
A study of the relationship between blood flow and limb volume in the hind limb of the dog.
}

J. P. Holt

University of Louisville

Follow this and additional works at: https://ir.library.louisville.edu/etd

Part of the Animal Sciences Commons, Biology Commons, and the Physiology Commons

\section{Recommended Citation}

Holt, J. P., "A study of the relationship between blood flow and limb volume in the hind limb of the dog." (1938). Electronic Theses and Dissertations. Paper 1791.

https://doi.org/10.18297/etd/1791

This Master's Thesis is brought to you for free and open access by ThinkIR: The University of Louisville's Institutional Repository. It has been accepted for inclusion in Electronic Theses and Dissertations by an authorized administrator of ThinkIR: The University of Louisville's Institutional Repository. This title appears here courtesy of the author, who has retained all other copyrights. For more information, please contact thinkir@louisville.edu. 


\title{
A STUDY OF THE PELATIONSHIP BETWEEI BIOOD \\ FLOV AND IIMB VOLUIE IN THE HIND IIMB OF IHE DOG
}

\author{
A Dissertetion \\ Submittod to the Faculty \\ of the Graduate School of the University of Louleville \\ In Partial Fulfillment of the \\ Requirements for the Degree \\ of Master of Science
}

Department of Physiology

By

J. P. Holt

1938 
Date Vune 4, 1938

Approved by

Committee :

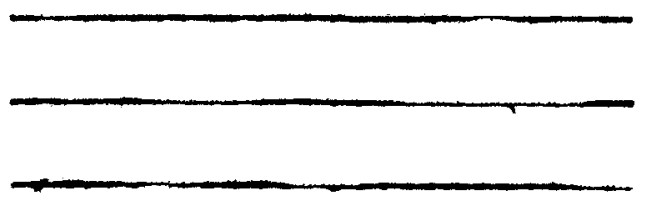

Bnglish Department 
A STUDY OF MHE RELATIONSHIP BETWEEN

BLOOD FLOW AND IIJE VOLUME IN

NHE HIND IIMB OF THE DOG 


\section{ACKNOWLEDGMENT}

It is a pleasure to acknowledge my gratitude to Doctor Hampden C. Laws on for his original suggestion, and for the sincere interest which he has evinced throughout the course of these studies. I wish also to thank all the members of the Department of Physiology and Pharmacology for the invaluable advice which they have so freely given.

J. P. Holt 
MABLE OF CONORNSS 
TABLE OF COMTENTS

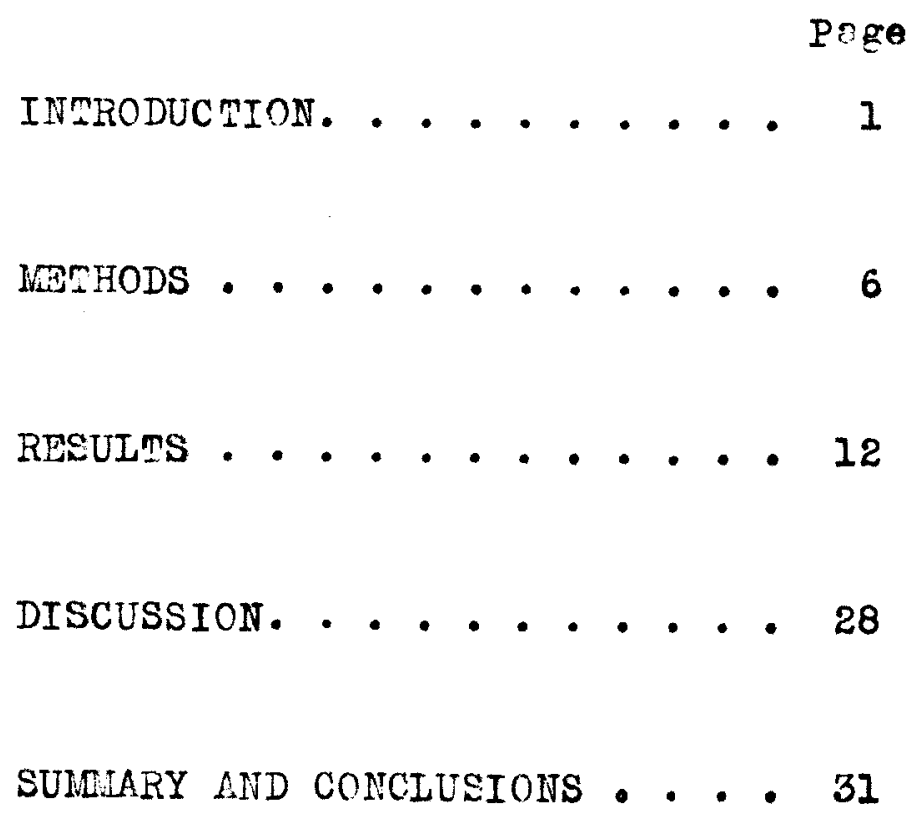

RIPERENCES. • • • • • • 32 
INIRODUC MION 
The view that the quantity of blood within the cranium is almost invariable wes expressed os early 881783 by Alexander Lonro (I). He wrote, "for being enclosed in a cese of bone the blood must be continually flowing out of the veing that room may be given to the blood which is entering the arteries. For as the substance of the brain. like that of the other solids of our body is nearly incompressible the quentity of blood within the herd must be the same or nearly the same at all times, whether in health or disegse, in life or after death, those cases only being excepted in which weter or other matter is effused or secreted from the blood vessels; for in these a quantity of blood equal in bulk to the effused matter will be pressed out of the cranium." This doctrine was supported by Kellie (l) who found that animals killed by bleeding had as much blood in the brain as those killed in other ways. But if the skull was trephined and the animals bled to death, on post mortem examination the brain appeared empty of blood. He concluded that so long as the cranium was closed the volume of blood in the brain could not vary. The conception of the invariability of the volume of the intracranial contents came to be known 88 the Monro-Kellie doctrine.

Hill (I) studied the cerebral circulation and found that a foreign body of two or three cubic centimeters volume could 
be added to the cranial contents of the dog without raising the intracranial pressure. The cerebral circulation was not changed with this added volume, presumably because cerebrospinal fluid was pushed from the ventricles into the spinal system, but if more than two or three cubic centimeters were added the venous sinuses were compressed, the cerebral caplilaries were obliterated, the intracranial pressure rose, and the cerebral circuletion wes disordered. Bayliss, Hill, and Guilland (I) took simultaneous recorda of the general arteriel, general venous, cerebrel venous, and intracrenial pressures and found no change in cerebral venous pressure on stimulation of the central and of the rago-sympathetic, the central end of the spinal cord cut at the level of the second to sixth dorsal nerves, and the cervical sympethetic nerve, that could not bo accounted for by the change in general orterial pressure. They concluded that the cerebral circulation followed passively the chenges in general arterial and general venous pressure, and in all physiological conditione a rise in arterial pressure accelerated the cerebral blood flow and a fall slowed it. No evidence for cerebral vesomotor nerves wes found.

Wiggers (2) showed in perfusion of the brain that epinephrine caused a reduction in venous return. Finesinger and Putnam (3) measured the blood flow into the brain of cets and monkeys by pumping heparinized blood into the internal carotid 
artery. The blood returned to the pump by way of the central end of the femoral or carotid artery. In this manner the perfusion pressure to the head was kept constent. They found that addition of epinephrine or pitressin to the perfusing fluid, or atimulation of the cervical sympethetic nerve caused decreased flow into the head, while the adition of caffeine or histamine to the perfusing fluid, or stimuletion of the central end of the vagus caused an increased flow. Gibbs and Lennox (4) measured the velocity of blood flow in the internal juguler vein in man using the Gibbs' thermo-electric blood flow recorder (5) and found an increased velocity of flow associated with incressed cerbon dioxide tension in arterial blood. The attributed this increase to an increase in the cerebral vascular bed.

While the volume of the cranial contents is relatively fixed, organs such es the spleen, kidney, limb, etc, are relatively free to chenge their volume. Oliver and schefer (6) showed that an intravenously administered extrect of the adrenal gland decreased spleen, kidney, and limb volume in the dog, and that it caused almost complete cessetion of flow of the circulating fluid in the arterioles of the frog. Hoskins and Gunning (7) showed thet intrevenous epinephrine caused diminution of the volume of the limb of the intact dog and decreased venous outflow from the skin ares. When the skin wes removed, 
epinephrine crused en increase in the volume of the limb and an increase in the blood flow from the muscles of the limb. The same investigatorg (8) working on the spleen showed a decreased volume and decreased venous ontflow from the spleen following the administration of epinephrine intravenously. Richards and Plant (9) perfused the limb of the dog with hirudinized blood at a constant volume of flow from \& perfusion pump and found that the perfusion pressure rose and the limb volume decreased when epinephrine wes added to the perfusing fluid.

It is generelly agreed thet in organs whose volume is eree to change, vesoconstriction, with reduction in the flow of blood, is associated with a reduction in the volume of the organ; and conversely, thet en increase in volume flow is associated with an increase in the volume of the organ. Indeod, oncometry, or the measurement of orgen volume, is a classical method for studying vasomotor chenges (10). There is no egreement, however, on the sential relationship between the volume change in the organ and the vasomotor change. Since volume changes accompany vesomotor chenges in most vascular beds, it may be argued that the two are inseparable. Most workers on the cerebral circuletion, in their application of the Monro-Kellie doctrine, have implied that since the instantaneous volume of blood within the cranium is relatively fiyed, the volume flow is governed only by the head of pressure, i.e., carotid blood pressure. The rich nerve supply to the cerebral vessels hes been supposed merely to shunt 
blood from one brain area to another, not to govern the total flow。

Since the work of Hill show 3 that considereble volume change can occur within the crenium without affecting total flow, the cerebral vasculer bed cannot be considered a bed of constant volume. It was decided, therefore, to attempt complete fixation of the total volume in a periperal vascular bed, for study of Ilow changes in the rbsence of volume change. 
MENHODS 
Dogs anesthetized with ether or soaium berbital were used. Blood flow was measured in one hind limb. Carotid blood pressure was taken with a mercury manometer. In the development of methods numerous unsuccessful experiments were done which are not reported here. Berly attempts were made at fixing the volume of the limb by placing it in a plaster of parle cast, and later by placing the limb and cost in a plethysmograph and applying negative preseures in the plethysmograph. It was thought that the negetive pressure would draw the limb out against the cast and thereby immobilize 1t. The cest was found to be relatively nonporous so gauze was substituted for the plaster. Elood flow was measured by the direct method of venous outflow, the thermo-stromunr ine thod as modified by Herrick and Baldes (II), and by the use of a differential manometer as explained below.

The thermo-stromuhr was found to be unsulted to this problew as it showed a paradoxical increase in flow when the limb was constricted below the stromuhr. No setisfactory explenation for this peradoxical effect has been found.

The principle of the Venturi-meter has previously been applied to the study of the velocity of flow in blood vessels (12, 13). E gless Venturi-meter of the conventional type may be inserted into a divided artery, which, of course, requires the use of an anticorgulant; or an oblicue ligeture may be 
thrown about the stem artery at the origin of a side ertery. In the latter case the side artery originating in the constricted portion of the stem vessel, and another side artery originating above the constriction are cannulated and led to the differential manometer. Under these conditions the difference in pressure is a function of velocity in the constricted portion of the stem vessel.

As it is auite difficult to place an oblique ligature about an artery, and to keep it from slipping, it was decided to make use of the fall in lateral pressure which occurs across the constricted portion of a vessel as a measure of velocity. As an mpirical comparison of the two methoas a model was set up with water flowing through a sys tem of rubber tubes past a constant constriction in the tubes. A side arm above the constriction was led to one limb of a differential menometer. In applying the Venturi principle, the other limb of the menometer was connected with a side arm leading off at the constriction. It was found that the pressure difference wes actually slightly greater for a given flow, if the lower limb of the menometer was connected below the constriction.

The differential membrane manometer is a modified pachon capsule (Fig. 1). It consisted of two tambours having their rubber membranes in apposition, with a light lever attrchod between the membranes. Eech tambour was filled with five per cent sodium citrate solution and connected through citrate-filled 
tubes to an arterial cannula; the upper tambour wos connectod with the carotid artery and the lower with the femoral artery. All side branches of the common ilisc, external ilinc, and femoral arteries were ligeted down pest the femorel trigono. With one femoral artery cannulated and led to the differential manometer, all the blood flowing pest the bifurcetion of the aorta thus passes into the opposite limb.

Although under certain conditions there mey be considerable: difference between leteral pressure in the carotid and the femoral artery (14), in the heavily barbitelized dog no difference was measured with our differential manometer. Furthermore, any slight difference in pressure wes unreleted to the velocity of flow in the femorel artery, since no change in the differential pressure occured on occluding the artery below the lower limb of the manometer. Such changes in corotid pressure as occured sponteneously under our experimentel conditions rere evidently closely panalleled by femoral pressure, since the differential remained unchanged for periods of observation lasting fifteen to thirty minutes.

The difference in pressure between the carotid and the femoral ertery may be expreseed as:

$$
\mathrm{H}=\frac{1 \mathrm{l} \mathrm{\nabla}^{2}}{\mathrm{~d} \cdot 2 \mathrm{~g}}
$$

where $H$ is the loss of heed, 1 is the length of the vessel, $\nabla$ is the velocity, $d$ is the diameter of the vessel, $f$ is a 
Fig. 1

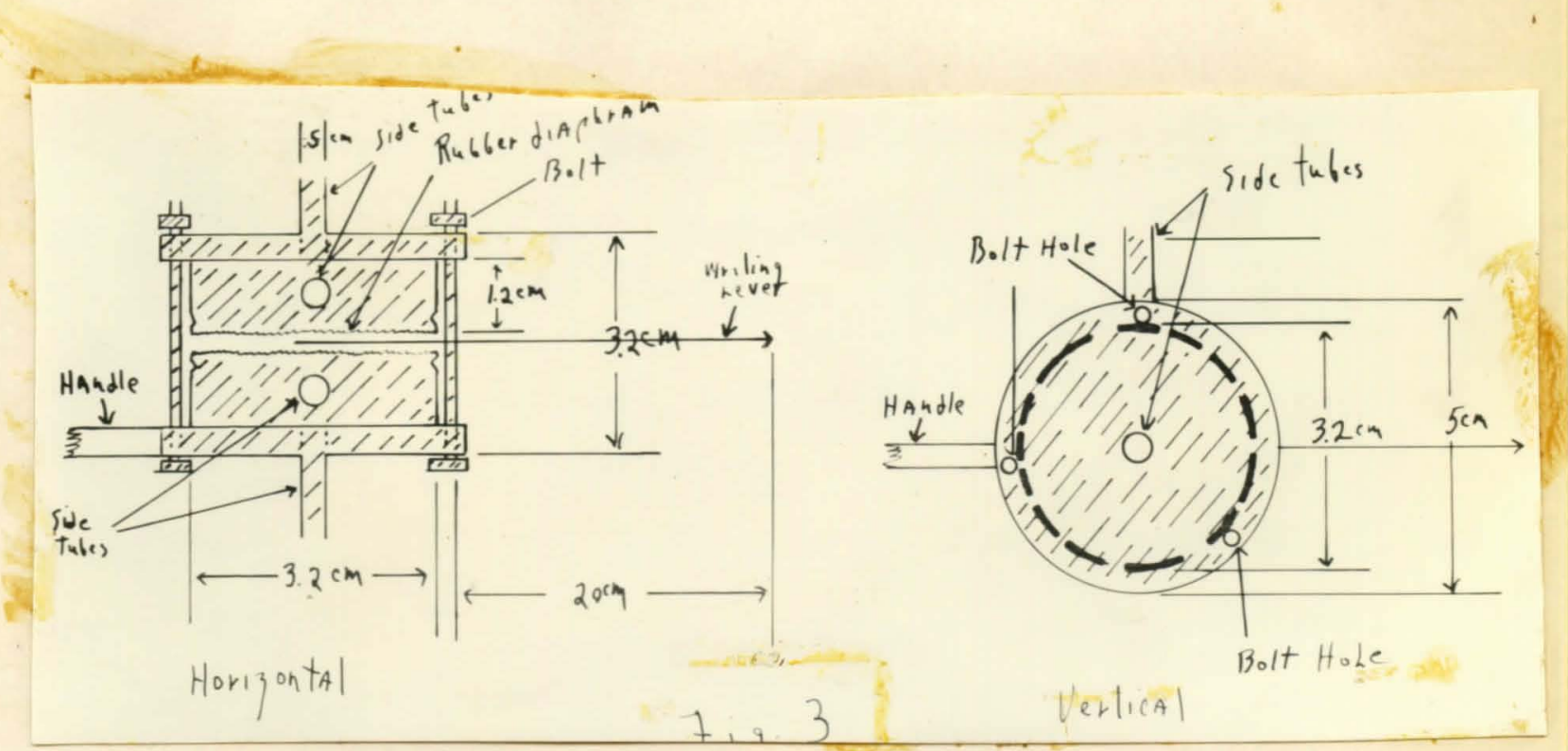

The Double Membrane Differential Menome ter 
constant depending on the roughness of the walls, and $g$ is the coefficient of acceleration due to grevity. The application of this formulation to the carotid-femoral differential pressure, however, is somewhat difficult, since neither velocity nor diameter are uniform throughout the intervening length of aorta. Without attempting a rigid formulation, it may be said that the 108s of head between these two points is a function of the velocity of flow between the carotid and femoral. Our observations suggest that under our experimental conditions the loss of head due to such changes in velocity remains practically constant.

A constriction was placed on the aorte just above the bifurcation by tying a string around the aorta or applying a screw clamp. The ligature or clamo was tightened until pressure fell in the femoral artery between five and ten millimeters of mercury. Mhis differential was immediately abolished by clamping the femoral artery below the constriction. If the femoral artery was opened and flow controlled with a screw clamp, the differential was found to be proportional to the flow. The flow meter was empirically calibrated in this wey at the end of each experiment.

It is justifiable to assume that a constant differential exists between the cerotid and the gorta just above the constriction, under the conditions of these experiments, and that 
chenges in the differential are due only to changes in velocity of flow through the constriction. Since all branches of the corta and the iliec below the constriction are tied oft except those eupplying the leg, the differential thus reads velocity of flow into the leg.

The loss of head due to a constriction in a tube is given as:

$$
\mathrm{H}=\left(\frac{a_{z}}{a^{z}}-j\right)^{2} \frac{\nabla^{2}}{28}
$$

where $a$ is the cross-section of the vessel, $a^{1}$ is the diminished cross-section at the constriction, and $\nabla$ is the velocity of the unconstricted portion. Since the cross-sections of the corte just above and just below the constriction are practically eaual, velocity above and below mey be taken to be equal. Hence the loss of head caused by the constriction is accurstely measured as the difterence in laterel pressure above and below. It is clear, therefore, that the difference in lateral pressure on the two sides of the constriction is a function of the velocity of flow in the femorel artery。 
RESULTS 
Two etherized dogs were given $300 \mathrm{mg}$. per kg. of body weight of the anticoagulant dye chicago blue $B 2$. One hind limb was placed in a plaster of paris cast which reached to about the proximal third of the femur. All branches of the common and external iliac arteries were tied, and all branches of the femoral artery as low as the lower third of the femur. The femoral vein was cannulated and the outflow measured. Section of the sciatic nerve increased venous return in each case. See Table 1.

A comperison of blood flow on the two sides (opposite leg not in a cast) showed that although the flow through the limb in the cast was greatly reduced (as much as one-twentioth) the percentage increase on section of the sciatic nerve was at least as great as in the limb which was not in a oast. The ectual increase in flow, in c.c. perfninute, however, was many times greater in the limb without a cast.

With the flow meter described above, the infection of nitroglycerine into the femoral artery, 2 c.c. of a $1 / 20$ dilution of the U.S.P. spirits, caused an increased blood flow in the limb in the cast. The blood pressure was constant during most of the period of increased flow, but began to fall slightly as the flow returned to normal.

Since the rolume of limb plus cast may heve been changing, a plethysmogreph connected to $a$ volume recorder was placed over 
the cast and sealed to the skin. Intra-arterial spirits of nitroglycerine caused an increase in flow without a recorded change in limb volume (Fig. 2). Since, if the cast were only difficultly permeable to air, small changes in volume of the limb within the cast might not have been transmitted to the volume recorder, negative pressures, of 145 to 170 millimeters of mercury were developed in the plethysmograph in the hope that the negetive pressure would draw the limb out tight against the cast and thus fix the limb volume. Intra-arterial nitroglycerine, 2 c.c. of a $1 / 20$ dilution of the U.S.P. spirits, caused an increased flow, and epinephrine hydrochloride, 1 c.c. of 1/50,000 solution, caused a decreased flow (Fig. 3). These drugs caused approximately the same change in flow whether negative or atmospheric pressure was in the plethysmograph. The plethysmograph was maie air-tight at its junction with the skin by tightly wrapping a wire around the rubber end of the plethysmograph. The femoral artery and vein were protected from the pressure of the wire by a brass tube which was placed around them (Fig・ 4).

The plester of paris wes tested for porosity and found to be relatively non-porous. The limb mey, therefore, have changed in volume in the ebove experiment if air pockets existed between the skin and the cast. It was thought that the limb volume might be fixed by wrepping the limb with porous but inelestic bendege, and exposing the wropped limb to large negetive pressures in the 
Fable 1

\begin{tabular}{|l|c|c|c|}
\hline & $\begin{array}{c}\text { Flow in c.c.per } \\
\text { minute before } \\
\text { scietic section } \\
\text { c.c./ min. }\end{array}$ & $\begin{array}{c}\text { Fow in c.c.per } \\
\text { minute after } \\
\text { sciatic section } \\
\text { c.c./min. }\end{array}$ & $\begin{array}{c}\text { Percentage } \\
\text { increase after } \\
\text { sciatic section } \\
\%\end{array}$ \\
\hline $\begin{array}{l}\text { I1mb in } \\
\text { cast }\end{array}$ & 9.8 & 12.7 & 29.5 \\
\hline $\begin{array}{l}\text { Iimb in } \\
\text { cast } \\
\begin{array}{l}\text { control limb } \\
\text { not in cast }\end{array}\end{array}$ & 2.2 & 4.1 & 86.4 \\
\hline
\end{tabular}

The chenge in outflow from the femoral vein on section of the sciatic nerve in limbe with and without plester cests. 
Fig. 2

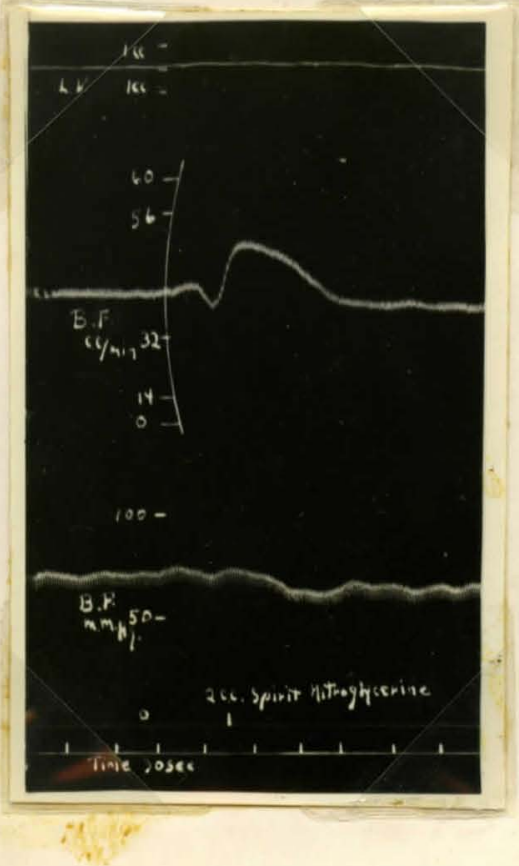

Iimb in plaster of Paris cast with plethysmograph over the cast moasuring volume change. I.V., limb volume. B.F., blood flow. B.P., blood pressure。 Time in thirty-second intervals. 
plethysmograph. If it could be assumed that the drop in plethysmograph pressure under these conditions produced no swelling of the leg, the force with which the surface of the leg was held to the bandage would be equal at least to the difference between atmospheric and plethysmograph preseure. If swelling occured, and elastic tissues in the leg were stretched by the drop in plethysmograph pressure, the force with which limb volume was fixed would be the above less the elastic recoll of the stretched tissues. It was found in preliminary experiments that a reduction in pressure on the Iimb (without bandages) caused a definite, though at times temporary, increase in blood flow. With the leg bandeged, 10w pressure was applied at increments of minus 50 to minus $100 \mathrm{~mm}$. of mercury, until no further change in flow occured. It was assumed that this marled cessation of swelling. Pressure was then dropped approximetely $100 \mathrm{~mm}$. of mercury further (F1g. 5). At this time, the force holding the surface of the leg against the bandage should have been equal to an excess pressure of 100 to $150 \mathrm{~mm}$. of mercury. This was equal to or greater than arterial pressure. Therefore, it was aseumed that no change in leg volume would occur as a result of even maximal changes in intravasculer pressure.

The changes in flow from intra-arterial epinephrine (Fig.6) and spirits of nitroglycerine (F1g. 7) were essentielly the same whether the bandaged limb was at atmospheric or at negative 
Fig. 3

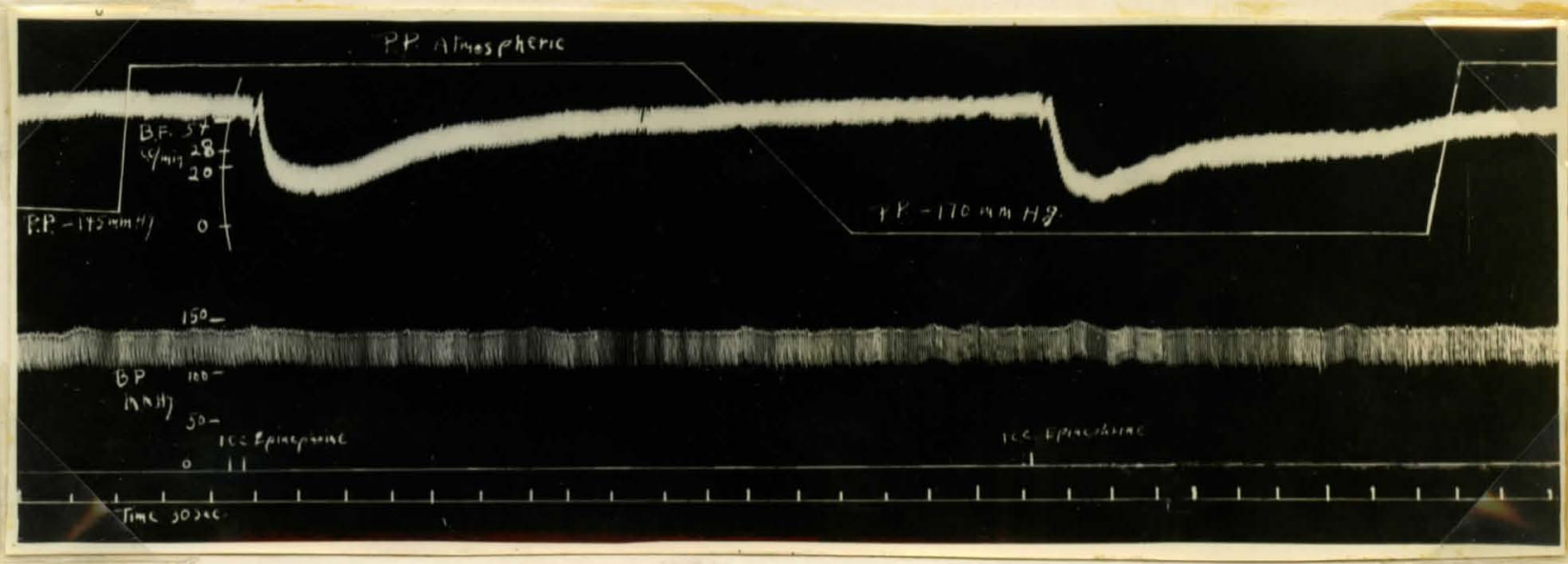

Iimb in plaster of peris cast with plethysmograph over the cast and negative pressure in the plethysmograph. P.P., plethysmograph pressure. B.F., blood flow, B.P., blood pressure. Time in thirty second intervals. 
Fig. 4

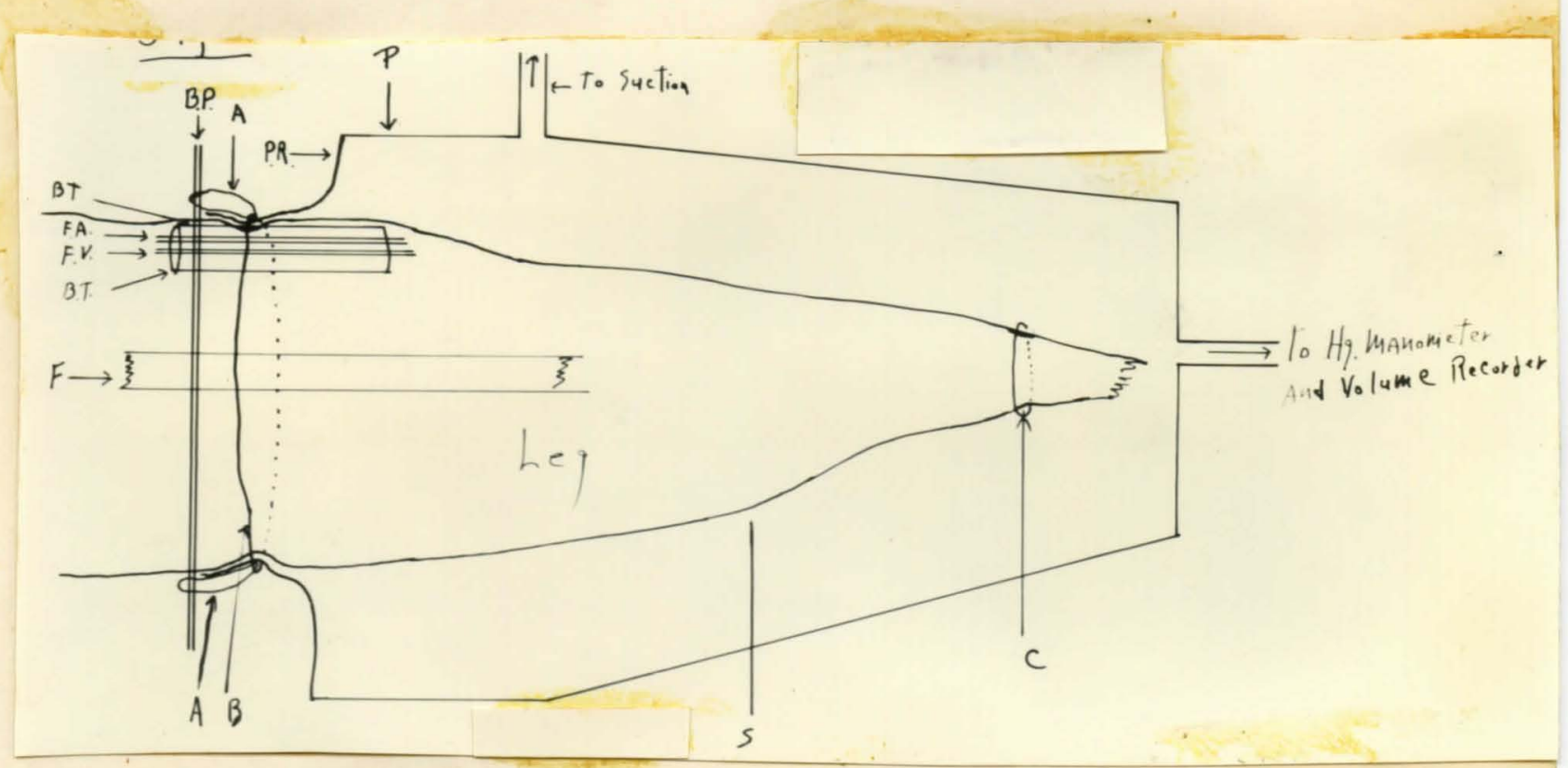

Limb in a plethysmograph with a wire around the rubber end of the plethysmograph to make an air-tight seal. Brass tube, with a longitudinal slit in it, around the femoral artery and vein to protect them from the pressure of the wire around the limb. Bone pin through the femur anchoring the brass tube and wires which anchor the wire that is around the limb. P.,plethysmograph. P•R., rubber end of plethysmograph. A., wire anchoring the wire that is around the limb to the bone pin. B.P., bone pin. B.T., brass tube. F.A., femoral artery. F.V., femoral vein. F., femur. B., wire around limb. S., skin. C., wire around foot. 
Fig• 5

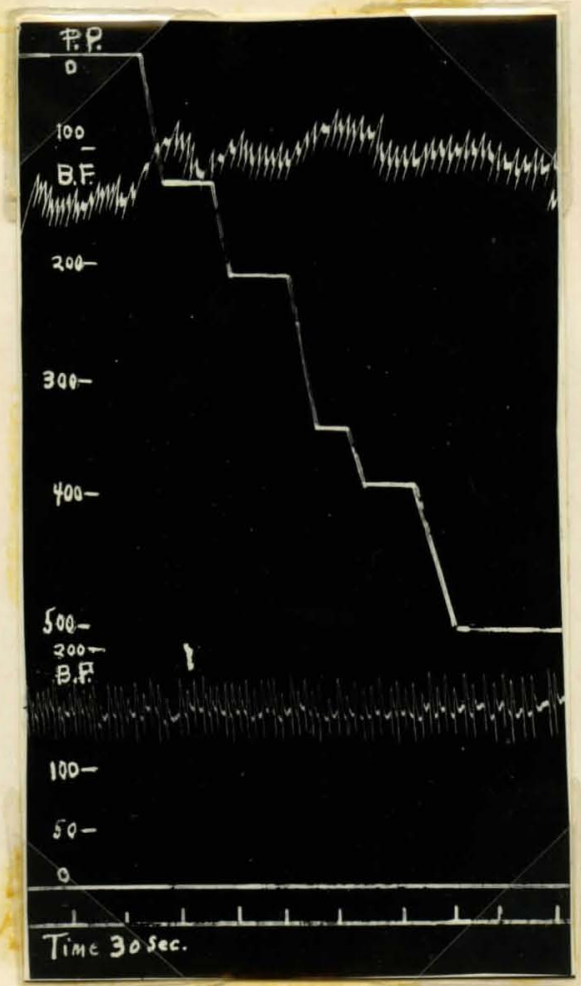

Iimb wropped with gruze and placed in a plethysmograph. The pressure in the plethysmograph is lowered in steps to minus $500 \mathrm{~mm}$. mercury. B.F., blood flow. P.P., plethysmograph pressure. B.P., blood pressure. Time is in thirty second intervals. 
pressure such as would be expected to fix limb volume. The negative preseure varied in different experiments botween minus 300 and $500 \mathrm{~mm}$. of mercury.

This demonstration is velid only if it can be assumed that there is actually an excess force fixing the leg against the bandage equal to or greater than blood pressure. Since there was no direct assurance that the leg plus bandage was ever fixed in volume, 1.e., since the forces acting at the surface of the bandaged leg might still have been at equilibrium, the experiment was not considered crucial. Attempts were made to measure the change in limb volume when epinephrine was given by weighing the leg. The leg, wrapped in gauze bandage and in a negative pressure plethysmograph, was amputated lesving only the femoral artery and vein intact. It was then suspended by a long spring balance which meavured the weight accurately to $500 \mathrm{mg}$. Out of ten infections of epinephrine, nine gave no change or a slight increase in weight and one gave a decrease in weight. Since a simulteneous satisfactory record of blood flow was not obtained in a single case, these date, although suggestive, are not conclusive. An attempt was made to measure the volume with the limb subjected to negetive pressure. The limb was wrapped with gauze and ploced in a water-filled plethysmograph connected by water-filled tubing to a mercury manometer. The open arm of the manometer was connected to a magnifying volume-recording tembour. Negative pressures were applied in the plethysmograph 
and the plethysmograph calibrated by ading or removing 1 c.c. of water. The volume-recording syetem was found accurate to 1 c.c. or less. With the limb under a negative pressure of $260 \mathrm{~mm}$. of mercury, intra-arterial epinephrine, I c.c. of $1 / 50,000$ solution, decreased flow from $100 \mathrm{c.c}$. to $2 \mathrm{c.c}$. per minute (Fig. 8) with no change in limb volume. When the pressure was brought to atmospheric and the epinephrine repeated the blood flow fell from $135 \mathrm{c.c}$. to $2 \mathrm{c.c}$. per minute and the limb volume decreased 4 c.c. (FIg. 9). When the mercury trap was removed from the volume recording system, in order to prevent any pressure change in the plethysmograph due to a volume change of the $1 \mathrm{imb}$, ond the epinephrine repeated, flow deoreased from $6 \mathrm{~b} \mathrm{c.c}$. to $15 \mathrm{c.c}$. per minute and the limb rolume decreased 8 c.c. (Fig. 10). Intra-arteriel nitroglycerine, 2 c.c. of a $1 / 20$ dilution of the U.S.P. spirits, with the limb under a negative pressure of $280 \mathrm{~mm}$. of mercury, increased flow from $125 \mathrm{c.c}$. to $180 \mathrm{c.c}$. per minute with no chenge in limb volume (Fig. 11). When the pressure was brought to atmospheric and the nitroglycerine repeoted, the blood flow Increased from $110 \mathrm{c.c}$. to $160 \mathrm{c.c}$. per minute and the limb volume increased 1 c.c. (Fig. 12). When the mercury trap was removed from the volume recording system, nitroglycertne increased flow from $70 \mathrm{c.c}$. to $130 \mathrm{c.c}$. per minute and the limb volume increased I c.c. (Fig. 13). 


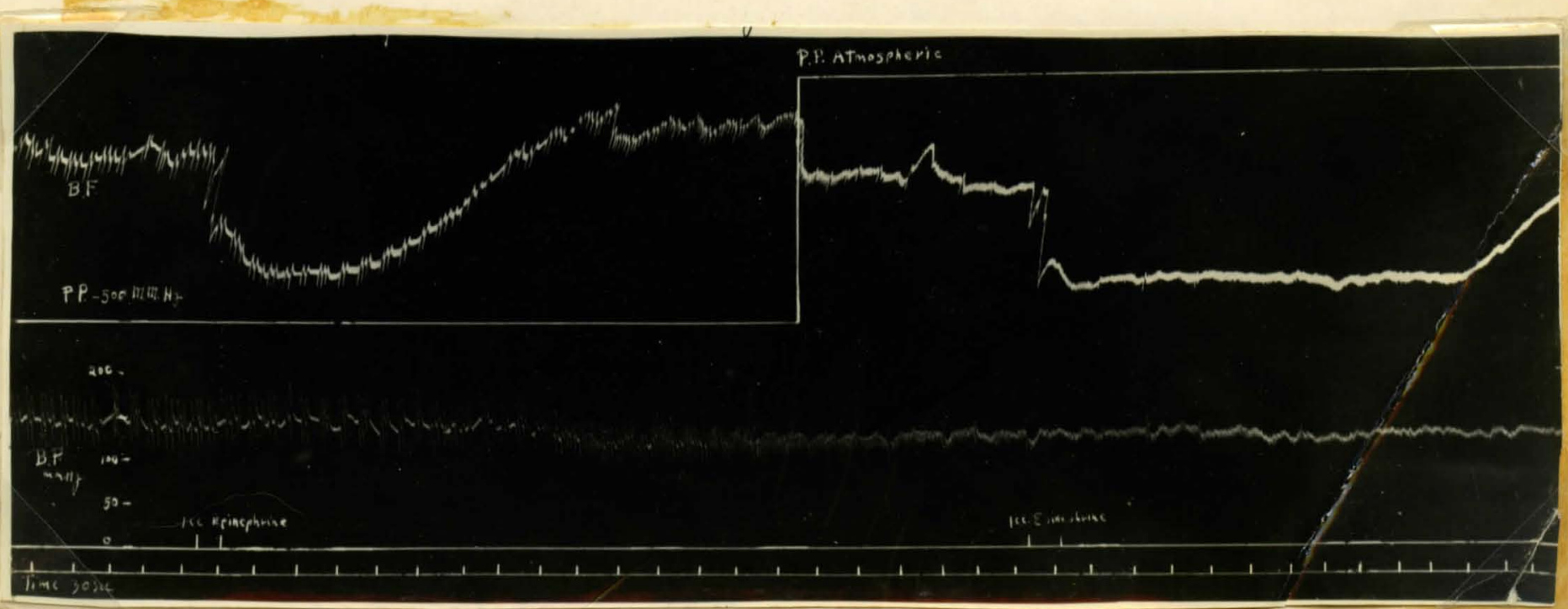

Iimb wrapped in gauze and placed in plethysmograph having negative pressures in it. P.P., plethysmograph pressure. B.F., blood flow. B.P., blood pressure. Time in thirty second intervals. 
Fig. 7

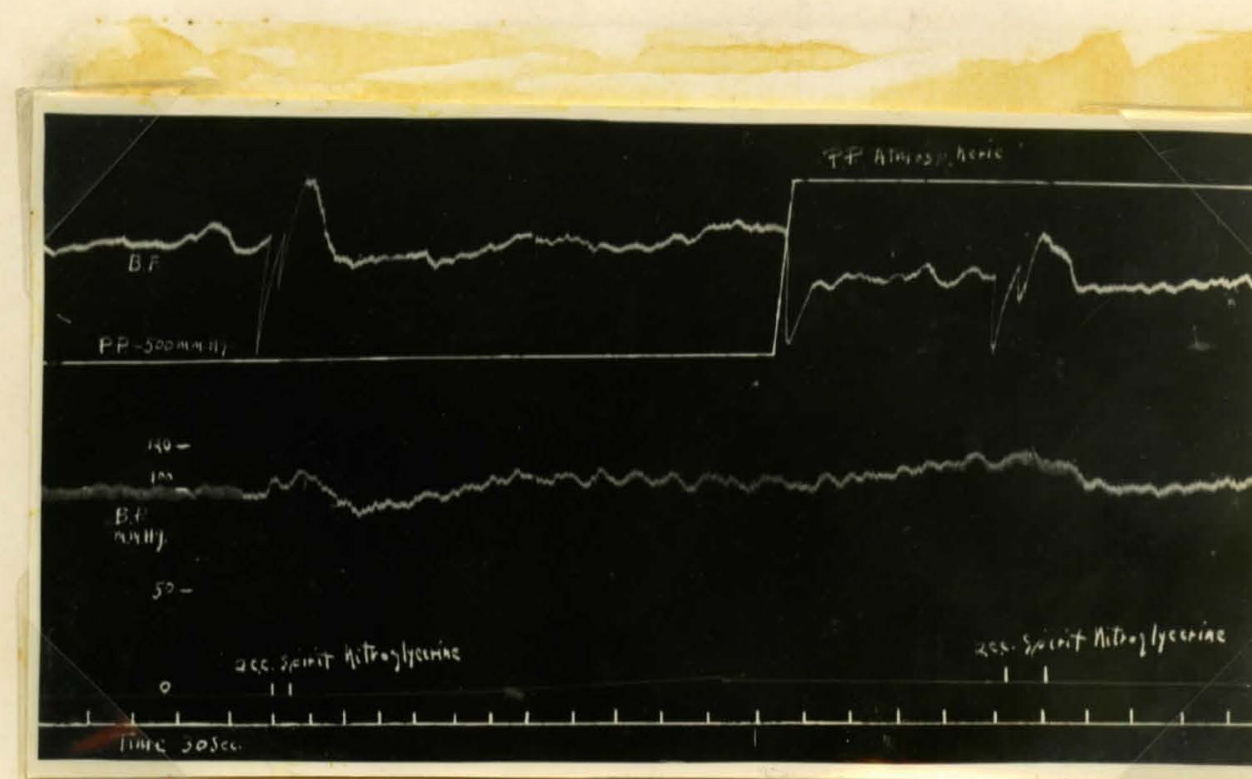

Limb wrapped in gauze and placed in a plethysmogreph having atmospheric and negative pressure in it. P.P., plethysmograph pressure. B.F., blood flow. B.P., blood pressure. Time in thirty second intervals. 
Fig: 8

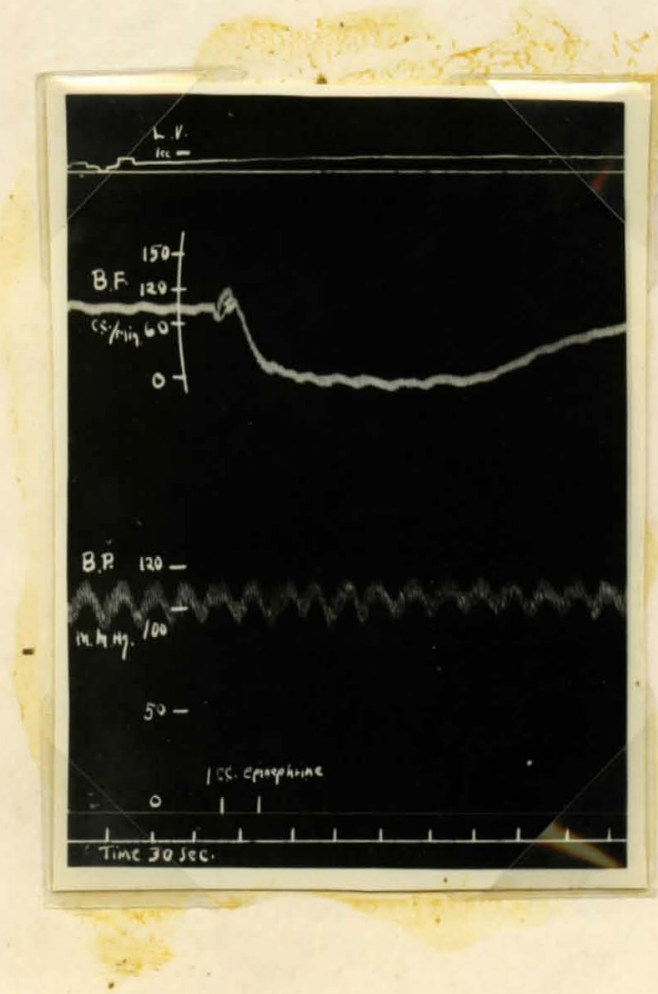

Iimb wrapped with geuze and placed in a water-filled plethysmograph at \& pressure of minus $260 \mathrm{~mm}$. of mercury. For limb volume measurement see text. I.V., limb volume. B.F., blood flow. B.P., blood pressure. Time in thirty second intervals. 
Fig. 9

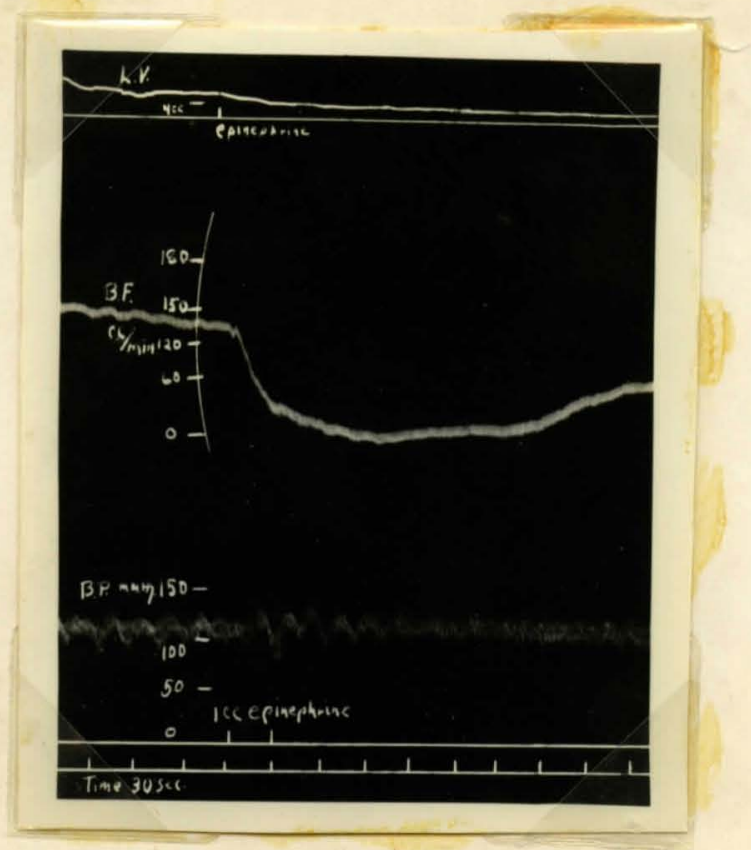

Same as Fig. 8 except that there is atmospheric pressure in the plethysmograph instead of negative pressure.

$$
\text { Pig. } 10
$$

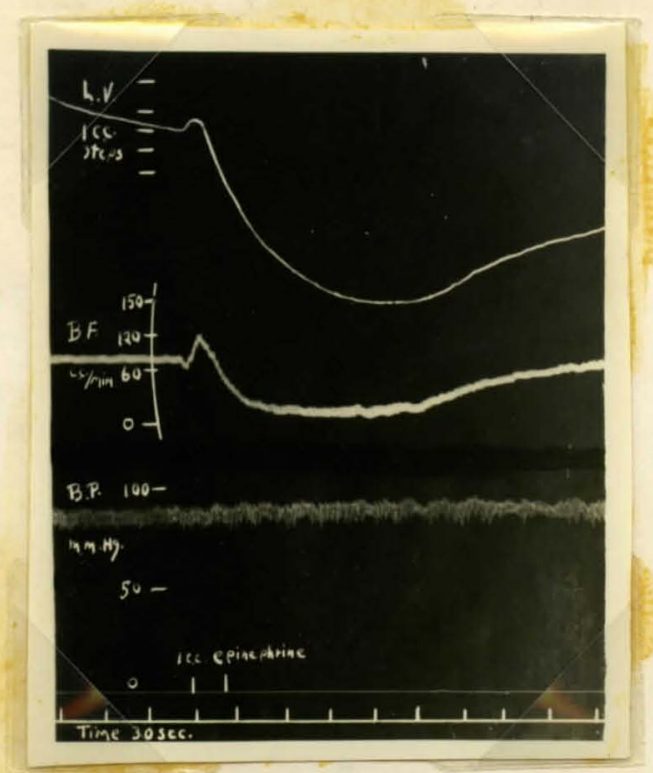

Same as Fig. 9 except that the mercury manometer has been removed from the volume recording system. 
Fig. 11

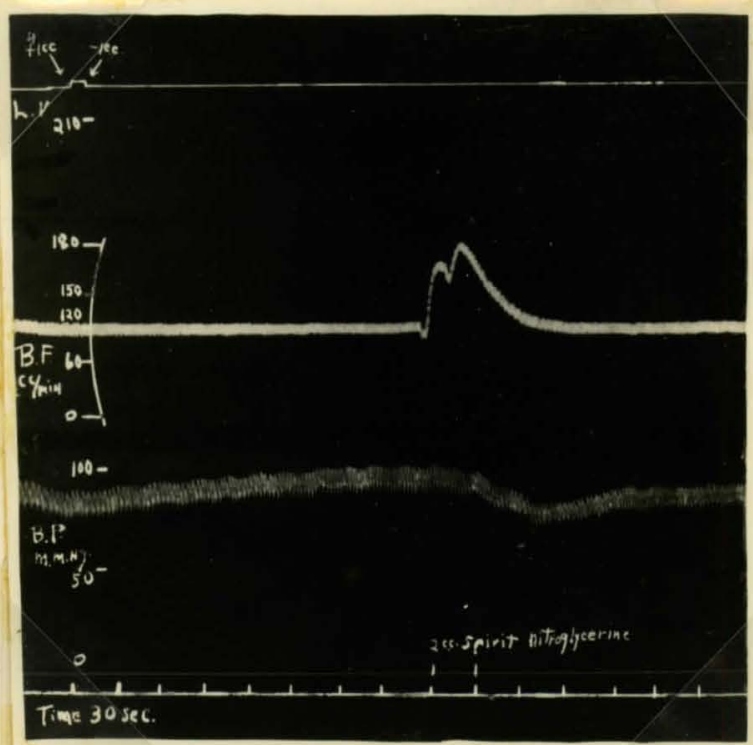

Iimb wrapped with gauze and placed in a water-filled plethysomograph with a negrtive pressure of $280 \mathrm{~mm}$. of mercury. B.F., blood flow. B.P., blood pressure. I.V., limb volume. Time in thirty second intervels. 
Fig. 12

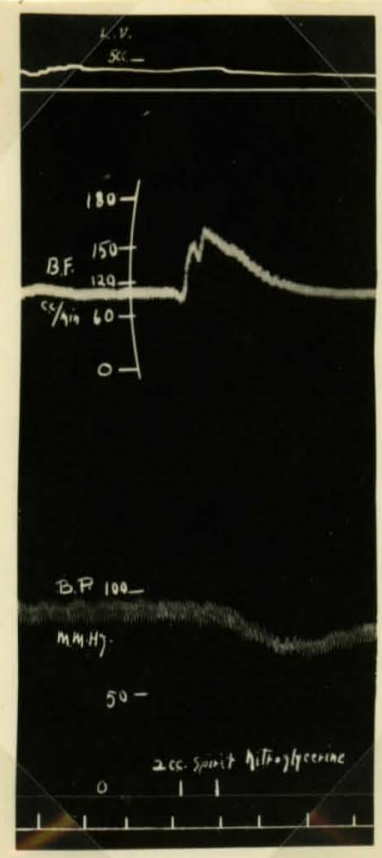

Same as Fig. 11 except that there is atmospheric instead of negative pressure in the plethysmograph.

\section{Fig. 13}

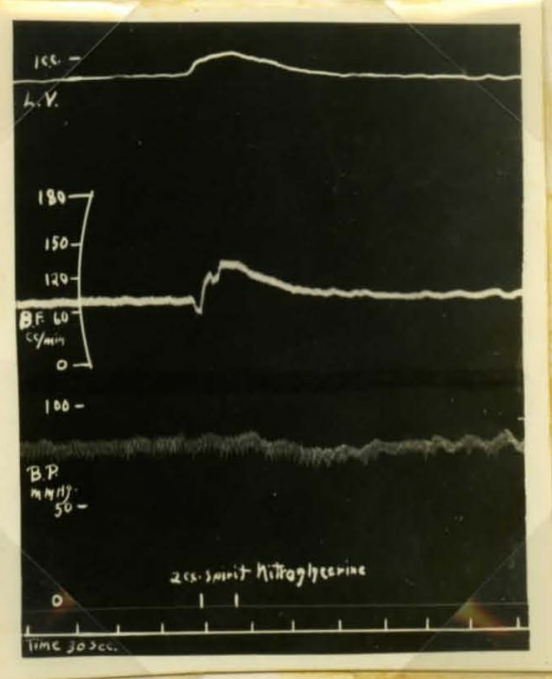

Same as Fig. 12 except that the mercury manometer has been removed from the volume recording system. 
DISCUSSION 
The implications of the Honro-Kellie doctrine as applied to the cerebral circulation are that within the rigidwalled cranium the total volume of flow is determined almost, if not entirely, by the head of pressure. It is conceded by most porkers on the cerebral circulation that velocity of total flow may be locally regulated by constriction of very short segments of vessele, probably arterioles, compensated by dilatation of others, probably veins. Deta proving such mechanisms, however, are scattered and inconclusive. It was expected, in the limb with fixed volume, that such mechanisms for looal control of velocity of flow would be active; the finding that such mechanisms are totally independent of the volume-changing mechanisms, however, was not expected.

It is generaliy believed that the local regulation of blood flow is primerily a function of the arterioles. Axcept in a few studies (9) no serious consideration has been given to the site of volume changes which normally accompany changes in blood flow. The data given here throw additional light on the latter question by suggesting that the segments in which the volume change occurs do not contribute significantly to the total peripheral resistance. If these data are accepted as showing that blood flow through the limb may change independently of limb volume and the head of pressure, it would seem that the fact that the cranial contents are relatively constant, as stated by the Monro-Kellie doctrine, is of little importance in 
the regulation of the cerebral circulation.

A criticism of the deta which cennot be definitely answered is that the negative pressure mey have held the skin rigid against the gauze bandrge and that gas may have been released in the tissues because of the negative pressure, or that air may have been drawn into the limb through the brass tube which was placed around the artery and vein. Under these conditions the contents of the $11 \mathrm{mb}$ may have changed in volume inside the skin by compressing or decompressing the gas, Wthout chenge in the recorded limb volumo.

The data on limb eights were expected to rule out this possibility. In nine ceses intra-arterial epinephrine caused a slight increase or no change in limb weight, when the volume was fixed by this method. This was interpreted to mean dilatation of the arterial segment because of the injection, sinco control injections of saline gave the same effect. In no experiment, however, were satisfactory simulteneous records of blood flow and leg weight obtained. This possibility, therefore, will have to be investigeted further.

This study hes been confined to only two vesculer drugs, epinephrine for vasoconstriction, ond nitroglycerine for vasodilatation. In view of Gibb's data on the cerebral circulation, showing that epinephrine does not change the flow, whereas carbon dioxide does, it is importent thet a large series of constrictor and dilator effects be studied. It is possible 
that, while with the two agents studied the effect on peripheral resistance and the effect on limb volume are independent, with other egents the two may be interdependent. 
SUIRLARY AND CONCLUSIONS 
(1) The blood flow through the hind limb of dogs anesthetized with ether or sodium barbital was measured by a diferential manometer method.

(2) Intra-arterial epinephrine decreased, and intraarterial spirits of nitro-glycerine increased the flow.

(3) The change in flow with these drugs was approximately the same with the limb free to change its volume and with the limb volume fixed.

(4) These data are presented as evidence that the blood flow through the limb can change with the $11 \mathrm{mb}$ volume remaining constant. 
REFERENCES 
(I) Bayliss, W.M., Hill, I., and Gulland, G.I. on intracranial pressure and the cerebral circulation. Journal of Physiology, 1895., 10: 334 .

(2) Wiggers, c. J. On the action of adrenaline on the cerebral vessels. American Journal of Physiology., 1905., 14: 452.

(3) Finesinger, J., Putnam, T. J. Cerebral Circulation.XXIII. Induced variations in the volume flow through the brain perfused at a constant pressure. Archives of Neurology and Psychiatry. 1933., 30: 775 .

(4) Gibbs, F.A., Gibbs, S.I., and Lernox, H.G. Changes in human cerebral blood flow coneequent on alterations in blood gases. American Journal of Physiology., 1935., 111: 557.

(5) Gibbs, F.A. A thermoelectric blood flow recorder in the form of a needle. Proceedings of the society for Experimental Biology and Medicine., 1933., 31: 141.

(6) Oliver, G., Schafer, E.A. The physiological effects of extracts of the suprarenal capsules. Journal of physiology., 1895., 18: 230 .

(7) Hoskins, R. G., Lee Gunning, R. E., and Berry, E.I. The effects of adrenin on the distribution of the blood. I. Volume changes and venous discharge in the limb. American Journal of Physiology., 1916., 41:513. 
(8) Hoskins, R. G., Iee Gunning, R.E. The effects of gdrenin on the distribution of the blood. II. Volume changeg and venous discharge in the spleen. American Journal of Physiology,, $1917 ., 43: 298$.

(9) Richards, A. N., Plant, O.H. Irine formation in the perfused kidney. The influence of adrenaline on the volume of the perfused kidney. American Journal of Physiology., 1922,, 59:184.

(10) Roy, C. S. The physiology and pothology of the spleen. Journal of Physiology., 1880-82., 3: 203.

(11) Baldes, E. J., Herrick, J. F. A thermostromuhr with direct current herter. Proceedings of the society for Experimental Biology and kedicine., 1937., 37:432.

(12) Daly, I, de Burgh, A blood velocity recorder. Journal of Physiology., 1926., $61 \stackrel{P}{:} 21$.

(13) Wagoner, G. W., Iivingston, A. C. Application of the venturifeter to measurement of blood flow in vessels. Journal of Pharmacology and Fxperimental Therapy., 1927-28., 32:171.

(14) Herrick, J. F., Cendy, J. B., Beldes, E. J., and Mann, F.C. Studies in differential blood pressure. Proceedings of the American hysiological society., 1938., p.97.

(15) Merriman, M. Treatise on Hydreulics. John Wiley and Sons Inc., New York, 1916. 